\title{
Evaluation of Susceptibility to Hydrogen Embrittlement-A Rising Step Load Testing Method
}

\author{
Wei Zhang1,2 \\ ${ }^{1}$ Mine Management Division, Department of Mining \& Mineral Resources, Chinalco China Copper Corporation \\ Limited, Beijing, China \\ ${ }^{2}$ Department of Mining and Materials Engineering, McGill University, Montreal, Canada \\ Email: zhang_wei@chalco.com.cn
}

Received 9 June 2016; accepted 2 August 2016; published 5 August 2016

Copyright (C) 2016 by author and Scientific Research Publishing Inc.

This work is licensed under the Creative Commons Attribution International License (CC BY). http://creativecommons.org/licenses/by/4.0/

(c) (i) Open Access

\begin{abstract}
Hydrogen embrittlement (HE) is a dangerous reaction that puzzled the material world for a long time. Hydrogen embrittlement is a type of deterioration which can be linked to corrosion and corrosion-control processes. It involves the introduction of hydrogen into a component, an event that can seriously reduce the ductility and load-bearing capacity, cause cracking and catastrophic brittle failures at stresses below the yield stress of susceptible materials. Presently this phenomenon is not completely understood and hydrogen embrittlement detection, in particular, seems to be one of the most difficult aspects of the problem. Although the process cannot be understand completely, method such as baking can reverse the process of hydrogen embrittlement and RSL (Rising Step Load) testing presents an excellent way to test the susceptibility to hydrogen embrittlement in the steel and its alloys. Different specimens were made to facilitate the testing. This study determines the effect of coating process have on the brittleness of the material and use of RSL (Risisng Step Load) mechanical loading test method to qualify plating processes for the risk of internal hydrogen embrittlement. The paper introduces the different causes of the hydrogen embrittlement, especially the zinc coating process and the hot dip galvanizing process. Subsequently, hydrogen embrittlement prevention and testing are discussed, as well as the current McGillestablished RSL (Rising Step Load) bend testing's principle, potential set-up, tested specimens and some of the critical results. Finally, some of the future development of the hydrogen embrittlement prevention will be covered.
\end{abstract}

\section{Keywords}

Hydrogen Embrittlement, Corrosion-Control, Coating Process 


\section{Introduction}

In today's world, the hydrogen embrittlement presents a bitter problem in the domain of almost all the high strength materials especially steel and its alloy. Although the hydrogen embrittlement mechanisms are understood, we still cannot find an appropriate process to completely eliminate it, nor do we find any composition of the high strength metal (e.g. steel) that is not susceptible to the hydrogen embrittlement. It is a dangerous reaction that puzzled the material world for a long time. It can be defined as the embrittlement of metal or alloy by atomic hydrogen that involves the ingress of hydrogen into a component [1]-[3], an event that the metal or alloy fails at load levels that are very low compared with those that a hydrogen-free metal or alloy can sustain. Hydrogen embrittlement is a type of deterioration which can be linked to corrosion and corrosion-control processes. It involves the introduction of hydrogen into a component; eventually it can seriously reduce the ductility and load-bearing capacity, cause cracking and catastrophic brittle failures at stresses below the yield stress of susceptible materials. Hydrogen embrittlement occurs in a number of forms but the common features are an applied tensile stress and hydrogen dissolved in the metal. Examples of hydrogen embrittlement are cracking of weldments or hardened steels when exposed to conditions which inject hydrogen into the component. Hydrogen embrittlement does not affect all metallic materials equally. The most vulnerable are high-strength steels, titanium alloys and aluminum alloys [4] [5]. Hydrogen embrittlement detection, in particular, seems to be one of the most difficult aspects of the problem [6].

Therefore, hydrogen embrittlement has been intensively studied since the nineteenth century. It has been found that the presence of hydrogen can reduce the ductility of materials. The embrittlement is sometimes reversible in the sense that the original ductility can be restored after the removal of hydrogen [3] [4]. To prevent the hydrogen effect in co-operation with an external stress, i.e. classical examples of these effects can be found in foundries, welding, electroplating, pickling, chemical processes, etc., flux shielded electrodes are usually stored at a temperature of $38^{\circ} \mathrm{C}\left(100^{\circ} \mathrm{F}\right)$ or higher. In some practices, electrodes which have been removed from the storage beyond a given time period or exposed to moisture, are required to be baked at $400^{\circ} \mathrm{C}\left(750^{\circ} \mathrm{F}\right)$ before being used or returned to the storage. Preheating is recommended to remove moisture from the weld joints especially, when welding is carried out in chilly mornings. In electroplating, hydrogen is usually liberated and absorbed in the substrate, i.e. the cathode. This occurs especially in an acidic plating bath and can cause delayed cracking. To reduce the effect of hydrogen, an alkaline plating bath is recommended for materials that are susceptible to hydrogen embrittlement. Baking after plating is sometimes effective in reducing the effect of hydrogen. In pickling of steels, the corrosion action of the acid on steels liberates hydrogen which can be absorbed and cause embrittlement. Organic inhibitors such as triazoles have been of industrial interest as an additive to the pickling tank to reduce both corrosion and the penetration of hydrogen in steels.

\section{Electrochemical Aspects of the Effect of Hydrogen on Metal}

Consider a corroding metal (anodic reaction) on the surface of which hydrogen reduction (cathodic reaction) occurs:

$$
H^{+}+e^{-} \rightarrow H_{(a d s)}
$$

The hydrogen atoms are formed and adsorbed on the metal surface. They may either combine with other hydrogen atoms to form hydrogen molecules $\left(\mathrm{H}_{2}\right)$ and diffuse away from the metal surface, or, dissolve into the metal to form adsorbed hydrogen inside of the metal. After the hydrogen atoms enter the inside metal, they concentrate at internal imperfections-voids where they combine to form hydrogen molecules [7]-[9]:

$$
2 H_{(a d s)} \rightarrow H_{2} \text {. }
$$

Thus the hydrogen gas can build up enormous pressures inside the void, and the void become a cavity, then a blister may be formed near the surface of the metal. Hydrogen embrittlement process commences with atomic hydrogen penetrating into metal (along the grain boundaries) and accumulated in distorted regions of the lattice. The sufficiently high pressure (voids in the lattice filled with hydrogen gas, the calculations show that the pressure can amount to thousands of atmospheres) causes initiate cracks and/or large cracks. When the metal is stretched, it does not yield like a ductile metal; it fractures along the ends. It is considered as: the hydrogen has embrittled the metal [3]. The schematic graph (Figure 1) about hydrogen blistering and embrittlement can be seen below. 


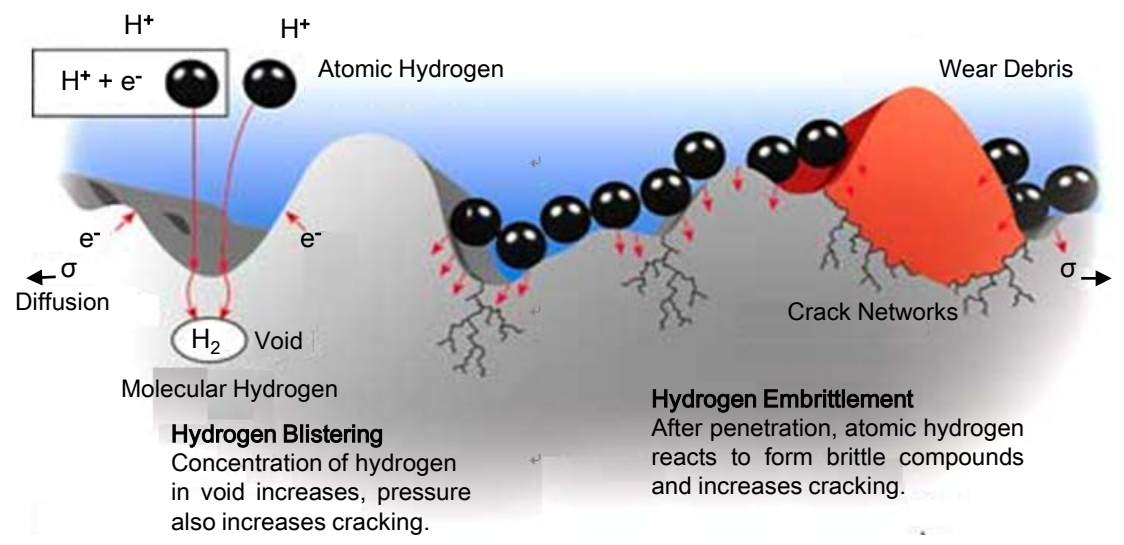

Figure 1. Schematic view of hydrogen embrittlement process [1].

Hydrogen embrittlement is not a permanent condition. If cracking does not occur and the environmental conditions are changed so that no hydrogen is generated on the surface of the metal, the hydrogen can rediffuse from the metal, so that ductility is restored.

\section{Hydrogen Embrittlement Prevention (On-Going Research)}

To address the problem of hydrogen embrittlement, emphasis is placed on controlling the amount of residual hydrogen in metal, controlling the amount of hydrogen pickup in processing, developing alloys with improved resistance to hydrogen embrittlement, developing low or no embrittlement plating or coating processes, and restricting the amount of in-situ (in position) hydrogen introduced during the service life of a part [4].

Electroplating is a major cause of hydrogen embrittlement. Some hydrogen is generated during the cleaning and pickling cycles, but by far the most significant source is cathodic inefficiency, which is followed by sealing the hydrogen in the parts. Baking is often performed on high strength parts to reduce this risk. For the Production plater, having to remove the parts from the production line to bake-followed by a separate chromating process is a laborious process [2].

For Nearly fifty years mechanical Plating has been accepted as a means of eliminating hydrogen embrittlement. Today, many specifications reflect industry's confidence in this unique process. While it is true that mechanical plating uses inhibited acids which generate less hydrogen, many believe that mechanical plating as a process is inherently free from hydrogen embrittlement because the deposit is porous (as are phosphate coatings), allowing hydrogen to escape through the coating.

The possibility of hydrogen embrittlement is an important consideration when high strength steels are electroplated. Plating processes generally have a current efficiency of less than $100 \%$ and a proportion of the current passed during electro deposition results in the generation of hydrogen, some of which becomes incorporated in the deposit and subsequently diffuses into the substrate. When hydrogen embrittlement is thought to be a risk, a de-embrittlement treatment may be required. Following cadmium plating, for example, steels with a tensile strength over $1800 \mathrm{MPa}$ are baked for 24 hours at a temperature in the range $190^{\circ} \mathrm{C}-230^{\circ} \mathrm{C}$ [7].

However, the baking process may not remove entirely of the hydrogen reside inside of the steel [5]. Sometimes, a coating process is preferred over the other process to reduce the effect of the hydrogen Embrittlement in the material.

Baking the zinc-cobalt coating that does not have an interlayer fails to restore its properties to those of the unplated controls. It is assumed that the presence of a thin layer of cobalt can have a significant effect. It is thought that a cobalt interlayer acts as a sufficient barrier to hydrogen that during baking the hydrogen in the coating escapes to atmosphere rather than diffusing into the steel [5].

\section{Hydrogen Embrittlement Testing Method}

Hydrogen embrittlement is present in almost all high strength metal. That's where the RSL (Rising Step Load) test comes to play. The purpose of the test is to measure the susceptibility of a metal or alloy to hydrogen-induced [7] [8]. The following specimens are used intensively in the hydrogen embrittlement testing. 


\subsection{F1940 Specimen (Figure 2)}

It's made of AISI 4340 steels. AISI 4340 steel is a heat treatable, low alloy steel containing nickel, chromium and molybdenum. It is known for its toughness and capability of developing high strength in the heat treated condition while retaining good fatigue strength. ASTM F1940 has been heat treated to a hardness of 50 - 52 HRC.

\subsection{F519 Specimen}

Have all the detailed specifications of F1940 except its Rocwell C hardness $=53-54$. A slightly increase in hardness lead to a more brittle material.

\subsection{The RSL (Rising Step Load) Testing Machine}

The RSL machine which located in Hot Deformation Lab in McGill University is a new breed of testing machine that can test the brittleness of the samples. Unlike the tensile strength machine, it exerts a bending force instead of axial force. As seen in Figure 3, the loading arm acts as a lever and while the bottom part of the load arm goes down, it put a bending force on the notched square bar samples.

The RSL bending machine uses four-pin system to apply force on the specimen. Figure 4 (a projection of area circled on Figure 3) is showing how the sample is broken:

As can be seen from the diagram, the loading arm put a force on the sample holder (grey part of diagram), by consequence, there are force apply on the four pin, therefore a bending force is created.

RSL test uses the basis of step-wise function. Its principal is quite simple. It starts out by increment certain amount of load and holds the load for a certain amount of time (Note that both the amount of load and amount of time is programmable by the user). The RSL test repeats this step until the specimen had yielded or broken.

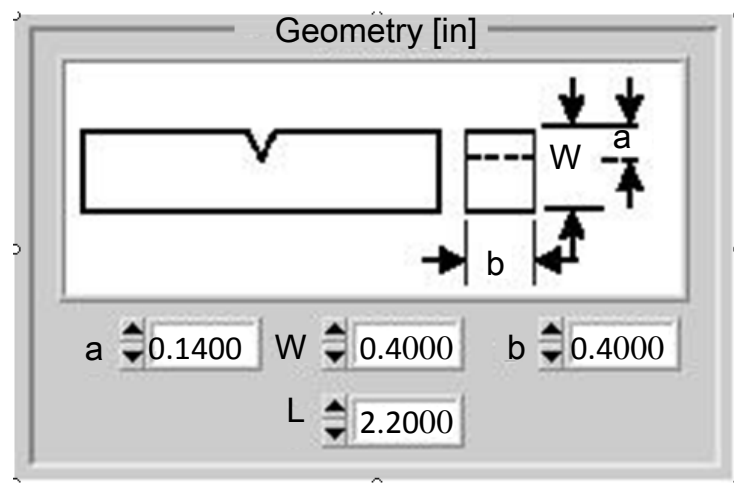

Figure 2. ASTM F1940 specimen.

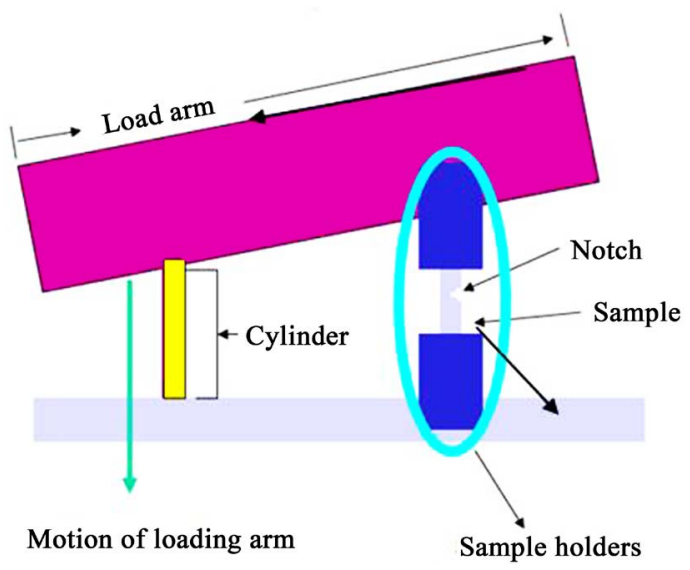

Figure 3. Schematic RSL testing machine diagram. 


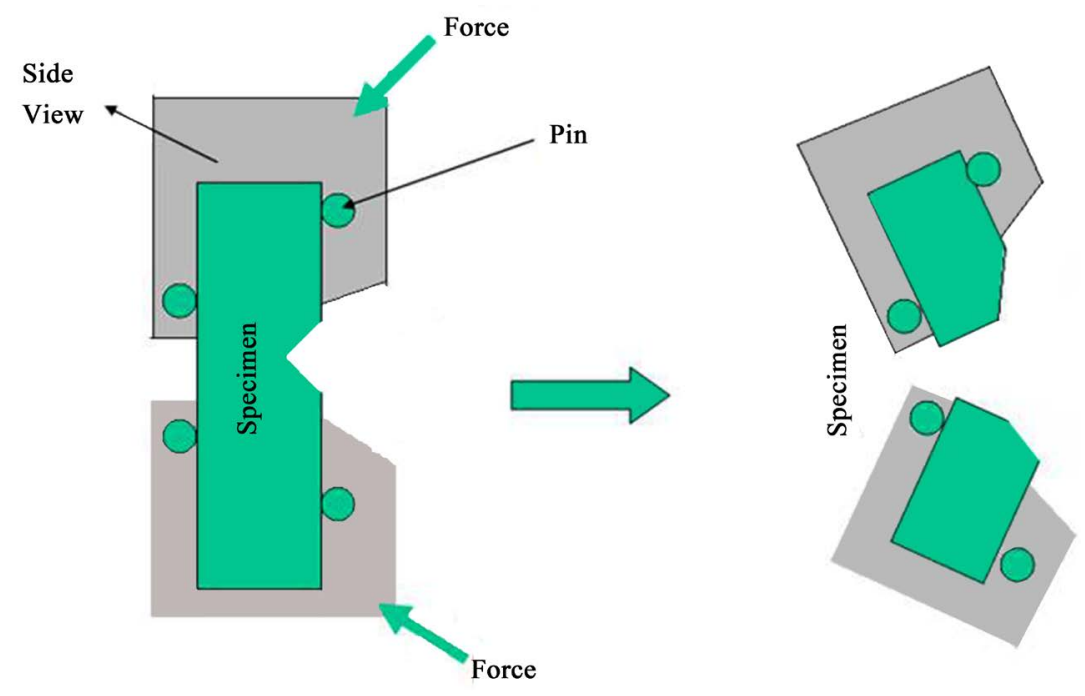

Figure 4. Force on the sample holder.

RSL test can be performing both in air and under potential [6]. The potential test is used to simulate the worst environmental condition that existed on earth by pumping $H$ ions into the sample. The max voltage is -1.2 volts. It's established experimentally that -1.2 volts can simulate the worst environmental condition on Earth. For the test under the potential, a special setup is required. We need to create a environment for the potential test and link it to the scientific controller of the RSL testing machine. The main purpose of the scientific controller is simulated hydrogen charging by applies potential and regulated the potential. The diagram (Figure 5) shows a graphical representation of the potential test setup on the RSL testing machine:

There are several different components that are very important for the potential test.

- Reference electrode (Saturated Calomel Electrode): measure the quantity of hydrogen ion in the solution, therefore the voltage.

- Auxiliary electrode: This is a platinum wire. Since platinum is a material that have high receptivity in corrosion. It acts as an anode.

- Instrumented bolt: use the line to connect it with the scientific controller. It acts as a cathode.

- Solution: solution used in most of the potential RSL test is $3.5 \% \mathrm{NaCl}$ solution. It acts as the medium of the current transfer.

The presence of cathode, anode and $\mathrm{NaCl}$ solution give the potential test a complete and closed circuits.

The usual testing curves for the hydrogen embrittlement are shown in Figure 6.

On this RSL test graph, the $\mathrm{X}$ axis is in hours. There are two $\mathrm{Y}$ axes on this graph, one is for the stress and the other one is for the load. From this graph, we can say that there is sudden and evident rupture of the specimen, on 152.2 second (fracturing time) and the instant load is $262.7 \mathrm{lb}$.

The results may imply two competitive crack initiation mechanisms exist for the effect of hydrogen. The first is the acquisition of a critical hydrogen concentration at the region with maximum triaxial stress at some distance below the notch root. This has been demonstrated in the high strength steels. It is showed that the crack was closer to the notch root when the notch was sharper. The second mechanism of crack initiation is that of a plastic instability assisted by hydrogen. Crack initiation at the notch root of a ductile bend sample is caused by a local plastic instability, which is perhaps determined by a critical gradient in shear strain. In the hydrogenated condition of the present work, the same is thought to occur except that the instability has been assisted by hydrogen. It was noted that the crack, in each case, started off the centre of the notch root and was at angle of about twenty five degrees from the crack direction.

Therefore, plastic instability has been the preferred mechanism for crack initiation in all the test conditions of the present work as crack initiation was observed at the notch root rather than at some distance below the notch root. With this mechanism, the critical strain required for plastic instability is expected to be higher for a more ductile material with a high rate of work hardening. Quantitative fractography is required for future work to verify the correlation of the plastic instability and the corresponding models. 


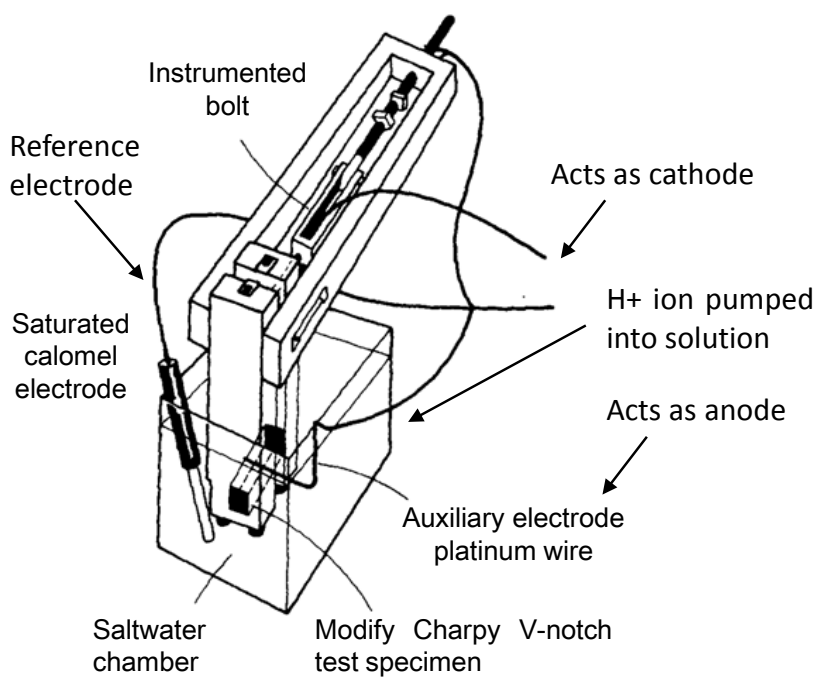

Figure 5. RSL potential test setup.

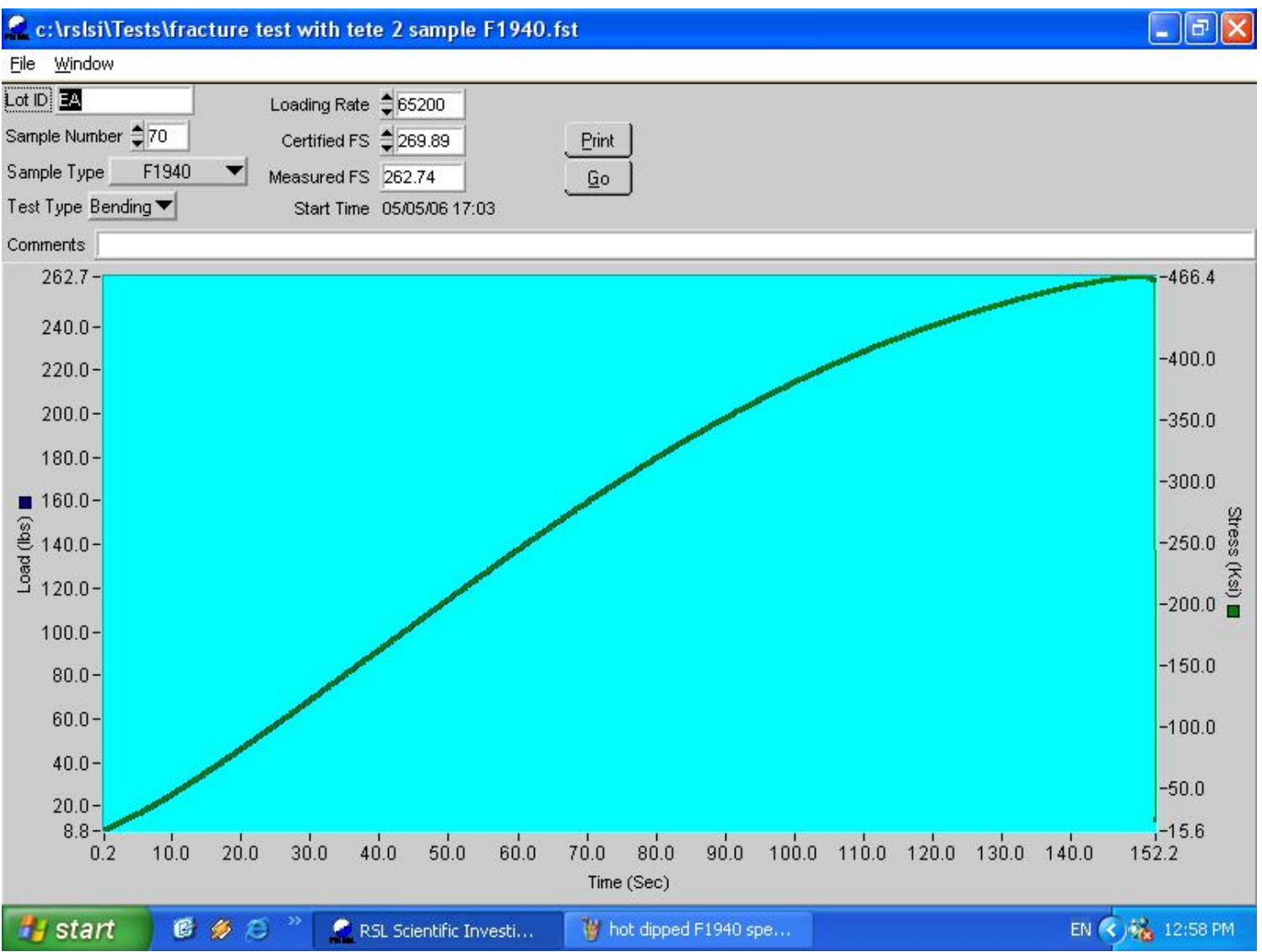

Figure 6. RSL testing curve.

\section{Conclusions}

1) Hydrogen embrittlement was introduced into single V-notched test samples by a standard RSL (Rising Step Load) mechanical loading test method. Hydrogen reduced the plastic strain required for crack initiation was also tested in this research.

2) Tests using a higher strain rate showed that hydrogen still promoted crack initiation but did not affect the 
rate of crack propagation. The orientations of inclusions played an important role in determining the path of crack propagation and delamination.

3) Hydrogen did not produce significant effect on the elastic modulus and the rate of work hardening of the steel. However, hydrogen lowered the average value of the maximum load of all the samples tested.

4) Plastic instability has been the preferred mechanism for crack initiation in all the test conditions of the present work.

\section{Future Work}

1) Quantitative fractography on samples tested in the charged and uncharged conditions would be helpful to verify the model of hydrogen in ductile fracture and its association with plastic instability for crack initiation.

2) To complete the analysis on the effect of baking, charged and uncharged samples in the baked condition should be tested. Higher baking temperatures such as $300^{\circ} \mathrm{C}$ to $350^{\circ} \mathrm{C}$ may be tried to completely remove the residual hydrogen so that the effect of "damage" caused by charging, if any, can be isolated.

3) The method used to dress the notch root radius was very tedious and sometimes produced notch roots of irregular shapes which may add variation to the test results. Improvement of the dressing technique is required.

\section{References}

[1] Dini, J.W. (1993) Electrodeposition: The Materials Science of Coatings and Substrates. Noyes Publications, Westwood, NJ, USA.

[2] Helmut, K. (2003) Corrosion of Metals: Physicochemical Principles and Current Problems. Springer, Berlin, New York.

[3] Raymond, L. (1988) Hydrogen Embrittlement: Prevention and Control. American Society for Testing and Materials, Philadelphia, PA.

[4] Timmins, P.F. (1997) Solutions to Hydrogen Attack in Steels. ASM International, Materials Park, OH.

[5] Raymond, L. (1998) The Susceptibility of Fasteners to Hydrogen Embrittlement and Stress Corrosion Cracking. In: Bickford, J. and Nassar, S., Eds., Handbook of Bolts and Bolted Joints, Chap. 39, Marcel Decker, Inc., New York, 723.

[6] Interrante, C.G. and Raymond, L. (1995) Hydrogen Damage. In: Baboian, R., Ed., Corrosion Tests and Standards, Chap. 27, ASTM International, Philadelphia, PA, 272.

[7] Tyler, P.S., Levy, M. and Raymond, L. (1991) Investigation of the Conditions for Crack Propagation and Arrest under Cathodic Polarization by Rising Step Load Bend Testing. Corrosion, 47, 82-86. http://dx.doi.org/10.5006/1.3585857

[8] Raymond, L. and Crumly, W.R. (1982) Accelerated, Low-Cost Test Method for Measuring the Susceptibility of HY-Steels to Hydrogen Embrittlement. Proceedings of the First International Conference on Current Solutions to Hydrogen Embrittlement in Steels, Washington DC, 1-5 November 1982, 477.

[9] National Materials Advisory Board (1976) Rapid Inexpensive Tests for Determining Fracture Toughness. NMAB 328, National Academy of Sciences, Washington DC. 


\section{Submit or recommend next manuscript to SCIRP and we will provide best service for you:}

Accepting pre-submission inquiries through Email, Facebook, LinkedIn, Twitter, etc.

A wide selection of journals (inclusive of 9 subjects, more than 200 journals)

Providing 24-hour high-quality service

User-friendly online submission system

Fair and swift peer-review system

Efficient typesetting and proofreading procedure

Display of the result of downloads and visits, as well as the number of cited articles

Maximum dissemination of your research work

Submit your manuscript at: http://papersubmission.scirp.org/ 